\title{
INFANTS WITH RECURRENT LOWER RESPIRATORY TRACT SYMPTOMS - WHO BENEFITS OF EXTENSIVE INVESTIGATIONS?
}

Anne Kotaniemi-Syrjänen, MD, Anna Pelkonen, MD, Kristiina Malmström, MD, Pekka Malmberg, MD and Mika Mäkelä, MD

Paediatric Respiratory Epidemiology Abstract Award, sponsored by Schering AG

Dept of Allergology, Helsinki University Central Hospital $(\mathrm{HUCH})$, Helsinki, Finland

WINNING ABSTRACT: There is limited information on lung function and exhaled nitric oxide fraction (FeNO) in infants with recurrent lower respiratory tract symptoms. In 2000-2003, 201 recurrently symptomatic infants were referred to a tertiary center for further investigation. As part of the clinical investigation, whole-body plethysmography, tidal FeNO measurements, and skin prick tests were performed. In addition, 77 (38\%) of the children underwent bronchoscopy. Increased work of breathing in clinical examination (in 22\%), and abnormal chest radiograph (in $30 \%$ ), were associated with decreased airway conductance (sGaw z-score $\leqslant-1.65)(p<0.001$ and $p=0.048$, respectively) and hyperinflation of the lungs $(F R C z$-score $\geqslant 1.65)(p=0.004$ and $p=0.038$, respectively). Exposure to environmental tobacco smoke (ETS) was associated with FeNO $\geqslant 40 \mathrm{ppb}(p=0.009)$. Increased work of breathing, sGaw z-score $\leqslant-1.65$, and FRC z-score $\geqslant 1.65$, were associated with low FeNO ( $p=0.002, p=0.005$, $p=0.026$, respectively). A definitive diagnosis was made in $184(92 \%)$ children; asthma was diagnosed in $149(74 \%)$, infection in $23(11 \%)$, and a structural abnormality in $12(6 \%)$. Abnormal findings in clinical examination predicted the diagnosis of asthma or a structural abnormality in $96 \%$ of cases, whereas in children with underlying respiratory infection or no definitive diagnosis, clinical examination was normal in $92 \%(p<0.001)$. In conclusion, clinical findings of bronchial obstruction predict well lung function and the diagnosis of asthma in recurrently symptomatic infants. FeNO is affected by ETS exposure, clinical state of the child, and the used methods, and the information obtained should be interpreted with care.

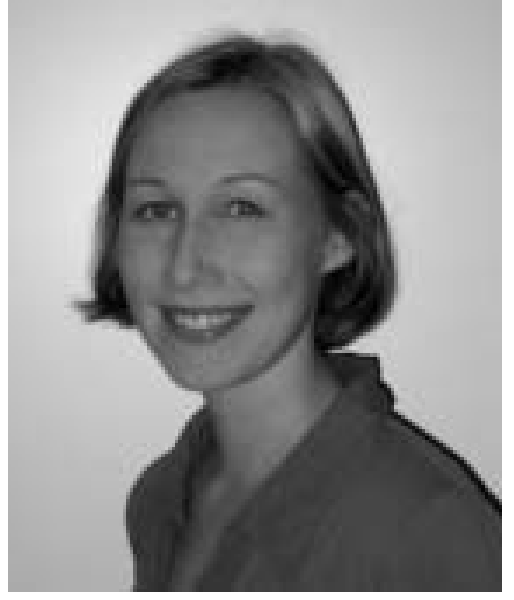

Anne Kotaniemi-Syrjänen

Dept of Allergology, Helsinki University Central Hospital (HUCH), Helsinki, Finland

\section{MY JOB AND THE UNIT IN WHICH I WORK}

I am a fellow at the Dept of Paediatrics in the HUCH Jorvi Hospital, Helsinki, Finland. Since 1999, I have been carrying out research on respiratory disorders in infants and children, first, as part of my PhD studies in the group of Professor Matti Korppi at the Dept of Paediatrics of Kuopio University Hospital, Kuopio, Finland, and, thereafter, since 2006, in the group of lecturer Mika Mäkelä in the Dept of Allergology at the HUCH Skin and Allergy Hospital.

STATEMENT OF INTEREST: None declared.

\section{MY RESEARCH AS PART OF MY WORKING GROUP/ RESEARCH TEAM}

When performing my $\mathrm{PhD}$ studies in the group of Professor Korppi, I focused on early childhood wheezing requiring hospitalisation: viral infections associated with wheezing [1, 2], outcome of wheezing [3], and the predictors of subsequent development of asthma [1, 3, 4]. We found that, in addition to respiratory syncytial virus, rhinoviruses also played a central role as inducers of wheezing in infants [1]. We also found that rhinovirus infection-associated wheezing was characterised by the following: 1) age $>12$ months, 2) the presence of atopic dermatitis, and 3) eosinophil activation during the episode of wheezing [5]. At the median age of $7 \mathrm{yrs}, 40 \%$ of the children hospitalised due to wheezing in infancy were regarded as having asthma [3], and our findings indicated that, in particular, wheezing due to rhinovirus infection in early childhood was associated with a significantly increased risk for the subsequent development of asthma [1]. In addition, blood eosinophilia, early childhood atopic dermatitis, elevated total serum immunoglobulin $\mathrm{E}$ and early sensitisation to inhalant allergens were found to predict persistent wheezing in hospitalised wheezy infants [3, 4].

At the HUCH Skin and Allergy Hospital, I have been carrying out postdoctoral research on recurrent lower respiratory tract respiratory symptoms in infants referred to a tertiary centre for further investigation. In the winning abstract, we aimed to characterise the nonselected children referred to our university hospital, and to evaluate lung function and exhaled nitric oxide fraction $(F \mathrm{eNO})$ in these children. We found that clinical findings of bronchial obstruction predicted fairly well lung function and the diagnosis of asthma in recurrently symptomatic infants. Conversely, FeNO was influenced by many different variables, 
e.g. clinical state of the child and the methods used, and the information obtained by FeNO measurements in symptomatic infants should be interpreted with care.

In recent years, our research team at the $\mathrm{HUCH}$ Skin and Allergy Hospital has been active in studying infants' respiratory physiology and pathophysiology [6-9], in developing new methods for clinical use [8], and in conducting intervention studies in paediatric respiratory medicine. Our research team consists of paediatric allergists, a clinical physiologist and a registered nurse.

\section{THE IMPACT OF MY WORK ON CLINICAL PRACTICE}

There is limited information on the use of lung function testing and exhaled nitric oxide fraction measurements in nonselected infants with recurrent respiratory symptoms. We hope that the information obtained in our study may help to identify those infants who might benefit from these specific investigations, as it is not possible to perform function testing and exhaled nitric oxide fraction measurements routinely to all children with recurrent respiratory symptoms.

\section{ACKNOWLEDGEMENTS}

I want to express my warm thanks to my co-workers Anna Pelkonen, Mika Mäkelä, Kristiina Malmström, Pekka Malmberg and Tuija Rito for the help in the baby asthma research project and for the constructive comments regarding my winning abstract. I also want to thank the European Respiratory Society (ERS) Paediatric Respiratory Epidemiology Group for the ERS Annual Paediatric Respiratory Epidemiology Abstract Award.

\section{REFERENCES}

1 Kotaniemi-Syrjänen A, Vainionpää R, Reijonen TM, Waris M, KorhonenK, Korppi M. Rhinovirus-induced wheezing in infancy - the first sign of childhood asthma? J Allergy Clin Immunol 2003; 111: 66-71.

2 Kotaniemi-Syrjänen A, Laatikainen A, Waris M, Reijonen TM, Vainionpää R, Korppi M. Respiratory syncytial virus infection in children hospitalized for wheezing: virus-specific studies from infancy to preschool years. Acta Paediatr 2005; 94: 159-165.

3 Kotaniemi-Syrjänen A, Reijonen TM, Korhonen K, Korppi M. Wheezing requiring hospitalization in early childhood: predictive factors for asthma in a six-year follow-up. Pediatr Allergy Immunol 2002; 13: 418-425.

4 Kotaniemi-Syrjänen A, Reijonen TM, Romppanen J, Korhonen K, Savolainen K, Korppi M. Allergen-specific immunoglobulin $\mathrm{E}$ antibodies in wheezing infants: the risk for asthma in later childhood. Pediatrics 2003; 111: e255-e261.

5 Korppi M, Kotaniemi-Syrjänen A, Waris M, Vainionpää R, Reijonen TM. Rhinovirus-associated wheezing in infancy: comparison with respiratory syncytial virus bronchiolitis. Pediatr Infect Dis J 2004; 23: 995-999.

6 Sagalami S, Malmström K, Pelkonen AS, et al. Airway remodeling and inflammation in symptomatic infants with reversible airflow obstruction. Am J Respir Crit Cure Med 2005; 171: 722-727.

7 Malmström K, Pitkäranta A, Carpen O, et al. Human rhinovirus in bronchial epithelium of infants with recurrent respiratory symptoms. J Allergy Clin Immunol 2006; 118: 591596.

8 Kotaniemi-Syrjänen A, Malmberg LP, Pelkonen AS, Malmström K, Mäkelä MJ. Airway responsiveness-associated features in infants with recurrent respiratory symptoms. Eur Respir J 2007; 30: 1150-1157.

9 Heier I, Malmström K, Pelkonen AS, et al. Bronchial response pattern of antigen presenting cells and regulatory $\mathrm{T}$ cells in children below two years of age. Thorax 2008; [Epub ahead of print PMID: 18250182]. 